\title{
Phytochemical analysis using GC-FID, FPLC fingerprinting, antioxidant, antimicrobial, anti- inflammatory activities analysis of traditionally used Eucalyptus globulus essential oil
}

\author{
Arun Dev Sharma ${ }^{1 *}$, Mohit Farmaha ${ }^{1}$, Inderjeet Kaur ${ }^{1}$, Narveer Singh $^{1}$ \\ ${ }^{1} P G$ Dept of Physics, Lyallpur Khalsa College, Jalandhar, Punjab, India \\ PG Dept of Biotechnology, Lyallpur Khalsa College, Jalandhar, Punjab, India \\ *Corresponding author: arundevsharma47@gmail.com
}

\begin{abstract}
Eucalyptus globules is a widely distributed in tropical and subtropical regions. It has been widely used as folk medicine, and folk cosmetic owing to its antioxidant values. Despite its importance, phytochemical and pharmacological studies remain infancy. This study was aimed at extraction of essential oil by hydro-distillation and evaluation of bioactive components, antioxidant, antimicrobial, anti-inflammatory activities along with analysis by Ultra-Violet (UV-VIS), Fourier-Transformation Infra-Red (FT-IR) and Fluorescent techniques. Fast protein liquid chromatography (FPLC) was used to confirm the presence of polyphenols. Different antioxidant activities like superoxide, nitric oxide and reducing power of the essential oil were also studied. In-vitro antimicrobial activity was also evaluated. FT-IR fingerprint qualitative analysis was performed using commercial standards. Considerable amount of flavonoids were detected in essential oil. Oil exhibited considerable DPPH (1,1-diphenyl-2-picrylhydrazyl), ABTS (2,2'-azinobis-3-ethylbenzothiazoline-6-sulphonate) scavenging activities and reducing power. UV-VIS, FT-IR analysis revealed the presence of polyphenolics in essential oil. Fluorescent spectroscopy revealed the presence of fluorophores in essential oil. FPLC and FT-IR fingerprint analysis revealed the presence of bioactive constituents like rutin, tannic acid, vanillic acid and ascorbic acid in the essential oil. A strong anti-inflammatory activity of oil was observed using fluorescent spectroscopy. An appreciable in vitro antibacterial activity against gram-negative bacteria like Acetobacter aceti and Pseudomonas aeruginosa was detected. The data provides the scientific support to the use of essential oil from Eucalyptus globules as a potent herbal source of bioactive compounds possessing natural antioxidant, anti-inflammatory, anti-bacterial activities in food and pharmaceutical industries.
\end{abstract}

Keywords: Eucalyptus globules, essential oil, flavonoids, reducing power, FT-IR, Fluorescent analysis, In-vitro antibacterial activity, anti-inflammatory activity.

https://doi.org/10.22456/2527-2616.110344

\section{Introduction}

Aromatic plants are most widely used as a source of traditional medicine (1). Literature survey revealed that, despite great progress in synthetic chemistry and western medicine, plants are still backbone of primary healthcare. Worldwide underutilized plants are widely used as traditional herbal medicine in villages (2). So detailed investigation of these underutilized plants is need of the hour especially in the developing and under developed counties, where primary healthcare strongly relays on traditional drugs as they are healthier, safer and more reliable than synthetic medicines. Consumption of these plants is increasing day by day for development of novel and biodegradable effective drugs as alternative to contemporary medicine. Medicinal plants contribution to phytomedicine has attracted significant amount of interest over the world (3). Medicinal plants have been used as important source of therapeutic drug molecules as they pose bio-active components which are potential source of drugs. The major bio-active components produced by these plants are alkaloids, flavonoids, phenols, saponins which are generally produced by plants as defense mechanism (4). These bio-active components are reported to suppress redox reactions of free radicals in biological systems. Herbal agents are complex mixture and their formulations are vital with respect to medicinal, nutrient and antioxidant values. Plant essential oils are secondary metabolites produced by aromatic plants. Essential oils are complex mixture of various bioactive chemical molecules such as hydrocarbons, aromatic derivatives, terpenes and their oxygenated derivatives such as mono- and sesquiterpenoids, alcohols and esters, alcohols and other aromatic compounds (5). Due to these diverse complex biostructures that act synergistically, essential oil poses various biological activities like antimicrobial, antiviral, fungicidal, insecticidal and herbicidal $(6,7)$. Essential oils are so named because they represent the very essence of odor and flavor of the plant. This essence of odor of oil comes from volatile substances like aliphatic and aromatic hydrocarbons, aldehydes, alcohols, esters and other constituents being emanated from flowers, seeds and bark of plants (8). Due to their herbal nature, safer alternative to chemical drugs, interest in these kinds of secondary metabolites in plants is increasing day by day. Essential oils are valuable natural produce of plants used as raw materials in several fields, together with perfumes, cosmetics, aromatherapy, botanical medicine, spices and nutrition, pesticides. Therefore, over the time a great interest has been paid to essential oils that may be used as therapeutic medicines (9). 
Sharma AD et al. / Drug Anal. Res., v. 5, n. 1, p. 26-38, 2021

Eucalyptus, member of Myrtaceae family, is a fast growing tree which reaches height up to 25-50 meters. This tree can grow in wide climatic conditions, and thrives best in tropical to temperate conditions. This tree can tolerate drought stress hence can be cultivated in drought areas and waste lands with temperature range from $0-47^{\circ} \mathrm{C}(8)$. The leaves of this plant are used to extract Oleum Eucalypti (Eucalyptus oil) worldwide. Essential oil (EO) from this aromatic plant has long history to be used as traditional medicine in ancient times. In addition, various potent biological activities including anti-bacterial, anti-oxidant, and anti-cancer, diaphoretic, disinfectant, anti-malarial, antiseptic, analgesic, anti-inflammatory, antibacterial, expectorant and antioxidant properties are attributed to Eucalyptus essential oil, hence playing a key role as therapeutics in the scientific community (8-11). Essential oil from Eucalyptus plants are great demand in market due to broad spectrum of applications like: flu, colds, muscular pain, expectorant in case of bronchitis (cough syryps), treatment of gum disease like "pyorrhea", mosquito repellent products, anodyne, deodorant, hemostat, fumigant, sedative, vermifuge, burns, boils, cancer, dysentery, diarrhea, inflammation, leprosy, malaria, soar throat, sores, spasm, wounds etc $(5,10)$. Patient from asthma are advised to inhale vapors of this oil as aromatherapy. It plays a very important antiseptic role in the preparation of menthol and thymol used in toothpastes. Worldwide it is also used in the preparation of aerosol which is used in chemical and varnishing industries (9). Although EOs from this plant has been empirically used as antimicrobial agent but its mechanism of action is still in infancy. So the objective of the present study is to extract essential oil from Eucalyptus globules and study its antioxidant, antimicrobial and anti-inflammatory activities.

\section{Experimental section}

\section{Extraction of Eucalyptus essential oil}

The fresh green leaf samples of Eucalyptus globule were collected growing under the natural conditions, from nearby areas of Lyallpur Khalsa College, Jalandhar located at $71^{0}$. $31^{0}$ east latitude and $30^{\circ}-33^{\circ}$ north longitude. The Eucalyptus globule was recognized by Dr Upma from Botany Dept and voucher with number BT102 was deposited in herbarium, of Dept of Biotechnology. Hydrodistillation method was used for extraction (in duplicate) of essential oil. Extraction was performed using Clevengertype apparatus. About $15 \mathrm{~g}$ of crushed green leaves were distilled at a working temperature of $100^{\circ} \mathrm{C}$ for $2 \mathrm{hr}$ with addition of $100 \mathrm{ml}$ of double-distilled water. The oil was collected from clevenger apparatus and stored at laboratory condition $\left(25^{\circ} \mathrm{C}\right)$. The oil obtained was used without further purification or filtration. Percentage yield of Eucalyptus essential oil have been calculated as follow; Yield $(\%)=$ weight of essential oil/

weight of leaves X 100

\section{Preliminary test (Qualitative analysis of phytochemicals)}

Eucalyptus globulus essential oil was dissolved in methanol $(0.3 \mathrm{ml} \mathrm{oil} / 2 \mathrm{ml}$ of methanol) and analyzed for the presence of various phytochemicals following Kumar et al, (11). Details of protocols used are cited in supplementary section.

\section{UV-VIS fingerprint analysis, FT-IR and Fluorescence spectroscopy analysis}

UV-VIS analysis of pure Eucalyptus oil was conducted using UV-VIS spectrophotometer (Labtronics) with slit width of $2 \mathrm{~nm}$, using a $10-\mathrm{mm}$ cell at room temperature and were examined in the wavelength ranging from 200-400 nm and peaks were recorded. FT-IR was used to identify functional groups. A small amount of oil was taken in the sample cup of a diffuse reflectance accessory. IR spectrum was obtained using FT-IR infrared spectrophotometer (Perkin Elmer, USA spectrophotometer). The sample was scanned from 4000 to $400 \mathrm{~cm}^{-1}$ and peaks were observed. The fluorescence spectrum of pure Eucalyptus oil was measured on Perkin Elmer Spectrophotometer (FL6500). All experiments were done at room temperature $\left(\sim 30^{\circ} \mathrm{C}\right)$.

\section{In vitro antioxidant assays}

Photochemical analysis of natural Eucalyptus oil was performed as described in literature. In order to investigate the antioxidant properties of oil, following assays were used. Since single assay never confirms antioxidant activity of any sample, hence different assays were used for the same.

\section{Nitric oxide scavenging activity}

The nitric oxide scavenging activity of Eucalyptus globulus essential oil was measured by the modified method of Obafemi et al, 2017 (12). Various amount of oil was taken. Sodium nitroprusside $(2.5 \mathrm{~mL}, 10 \mathrm{mM})$ in phosphate buffered saline (PBS) was mixed with different amount of oil. The reaction mixture was allowed to incubate at $25^{\circ} \mathrm{C}$ for $150 \mathrm{~min}$. Thereafter $0.5 \mathrm{~mL}$ aliquot was mixed with $0.5 \mathrm{~mL}$ of Griess reagent and the absorbance was measured at $546 \mathrm{~nm}$. Sodium nitroprusside in phosphate buffered saline $(2 \mathrm{ml})$ was taken as control. Ascorbic acid was taken as standard. The nitric oxide scavenging activity of the oil is calculated by the following equation. Percentage of inhibition $=\left[\left(\mathrm{A}_{0}-\mathrm{A} 1\right) / \mathrm{A} 0\right] \times 100$, Where $\mathrm{A} 0$ is the absorbance of sodium nitroprusside in PBS and A1 is the absorbance in the presence of oil.

\section{Superoxide radical scavenging activity}

Superoxide radical scavenging activity of various amount of Eucalyptus globulus essential oil was measured by nitroblue tetrazolium reduction method (13). One milliliter of nitroblue tetrazolium (NBT) solution (1 M NBT in 100 
mM phosphate buffer, $\mathrm{pH} 7.4), 1 \mathrm{~mL}$ NADH solution (1 M NADH in $100 \mathrm{mM}$ phosphate buffer, $\mathrm{pH}$ 7.4) was added to various amount of oil $(100-300 \mu \mathrm{L}) .100 \mu \mathrm{L}$ of phenazine methosulfate (PMS) solution $(60 \mu \mathrm{M}$ of PMS in $100 \mathrm{mM}$ of phosphate buffer, $\mathrm{pH}$ (7.4) was added to reaction mixture to start the reaction. The reaction mixture was incubated at $25^{\circ} \mathrm{C}$ for $5 \mathrm{~min}$. After that absorbance of the mixture was measured at $560 \mathrm{~nm}$. All reagents except PMS were taken as blank. For negative control only solvent was added, and for positive control, sample was replaced by ascorbic acid. All the measurements were made in triplicate. The superoxide radical scavenging activity was determined by using following equation. \% superoxide radical scavenging activity $=(1$-Absorbance of sample at $560 \mathrm{~nm}$ /Absorbance of control at $560 \mathrm{~nm}) \times 100$.

\section{DPPH radical scavenging activity}

The free radical scavenging activity of Eucalyptus globulus essential oil is determined by the using 1, 1-diphenyl-2picryl-hydrazyl (DPPH) assay (13). $2.8 \mathrm{ml}$ of DPPH solution (3.2 mg DPPH in $100 \mathrm{~mL} 82 \%$ of methanol) was added to various amount of oil $(50-100 \mu \mathrm{L})$. The mixture was allowed to stand in dark at controlled room temperature

$\left(25-27^{\circ} \mathrm{C}\right)$ for $1 \mathrm{hr}$ and measured at $517 \mathrm{~nm}$. Mixture of 3.0 $\mathrm{mL}$ of $82 \%$ of methanol was taken as blank while $3.0 \mathrm{~mL}$ of DPHH was taken as control. Ascorbic acid was taken as positive control. The test was performed in triplicate. Percentage inhibition was determined by the following formula. $\%$ scavenging $=$ Abs. of control - Abs. of sample $\times 100 /$ Abs. of control.

\section{ABTS radical cation assay}

ABTS radical cation assay was conducted using the protocol given by Khan et al, (13). According to the procedure, ABTS (2,20-azinobis-(3-ethylbenzothiazoneline-6-sulphonic acid, $7.4 \mathrm{mM}$ ) used as to provide free radical when treated with potassium persulfate $(2.45 \mathrm{mM})$ to form free radicals. $3 \mathrm{~mL}$ of this reagent was added in glass tubes with one tube having $3 \mathrm{~mL}$ ethanol as blank. Initial absorbance of reagents using glass corvettes was recorded at $414 \mathrm{~nm}$. Various amount of Eucalyptus globulus essential oil $(10-25 \mu \mathrm{L})$ was added to the reagent. The mixture was shaken thoroughly and absorbance of the mixture was measured using UV-VIS spectrophotometer at $414 \mathrm{~nm}$ after 90 minutes. Ascorbic acid was taken as standard. \% ABTS scavenging ability $=(\mathrm{A} 1$ A2/A1) $\times 100$, Where A1 is the absorbance of the control (ABTS solution without oil), and A2 is the absorbance in the presence of the test sample.

\section{Hydroxyl radical scavenging activity}

Hydroxyl radical scavenging activity of Eucalyptus globulus essential oil was calculated by the procedure given by Obafemi et al, (12). According to the procedure, hydroxyl radical is produced in a mixture of $1.0 \mathrm{~mL}$ of $0.75 \mathrm{mM} 1,10$ - phenanthroline, $2.0 \mathrm{~mL}$ of $0.2 \mathrm{M}$ sodium phosphate buffer $(\mathrm{pH} 7.4), 1.0 \mathrm{~mL}$ of $0.75 \mathrm{mM} \mathrm{FeSO} 4$ and $1.0 \mathrm{~mL}$ of $\mathrm{H}_{2} \mathrm{O}_{2}$ $(0.01 \% \mathrm{v} / \mathrm{v})$. After addition of different amount of Eucalyptus globulus essential oil (10-30 $\mu \mathrm{L})$, the mixture was incubated at $37^{\circ} \mathrm{C}$ for $30 \mathrm{~min}$. De-ionized water was used as the blank. Ascorbic acid was taken as positive control. The hydroxyl radical scavenging activity is calculated by the following equation. Scavenging activity $(\%)=($ Abs sample - Abs blank $) /($ Abs0 - Abs blank $) \times$ 100, Where Abs0 is the absorbance of deionized water instead of $\mathrm{H}_{2} \mathrm{O} 2$ and sample in assay system.

\section{Iron reducing power}

Iron reducing power of the Eucalyptus globulus essential oil was calculated by the procedure given by Obafemi et al, (12). According to the method different amount of Eucalyptus globulus essential oil (10-25 $\mu \mathrm{L})$ was mixed with $1.25 \mathrm{~mL}$ of $200 \mathrm{mM}$ of $\mathrm{NaPO}_{4}$ buffer (pH 6.6) and $1.25 \mathrm{ml}$ of potassium ferricyanide $(1 \%)$. Then the mixture was incubated at $50^{\circ} \mathrm{C}$ for 20 minutes and $2.5 \mathrm{~mL}$ of trichloroacetic acid $(10 \% \mathrm{w} / \mathrm{v})$ was added and was centrifuged at $650 \mathrm{rpm}$ for $10 \mathrm{~min} .100 \mu \mathrm{L}$ of $0.1 \%$ ferric chloride and $500 \mu \mathrm{L}$ deionized water was added to $500 \mu \mathrm{L}$ of upper layer and absorbance was taken at $700 \mathrm{~nm}$. Higher absorbance indicates higher reducing power. The assay was carried out in triplicates. Ascorbic acid was used as standard.

\section{Total phenolic content}

The total phenolic content of the Eucalyptus globulus essential oil was measured by the Folin- Ciocalteu method (14). Briefly, $50 \mu \mathrm{L}$ of oil was made up to $3 \mathrm{~mL}$ with double distillated water and then mixed properly with 0.5 $\mathrm{mL}$ of 1:10 Folin-Ciocalteu reagent and incubated for 3 minutes. After incubation, $2 \mathrm{~mL}$ of $20 \%(\mathrm{w} / \mathrm{v})$ sodium carbonate was added. The resulting solution was incubated for 60 minutes in the dark before absorbance readings were measured at $650 \mathrm{~nm}$. Gallic acid $(5-50 \mu \mathrm{g} / \mathrm{mL})$ was used in the calibration curve. Result were expressed as $\mathrm{mg}$ gallic acid (GAE)/10kg fresh weight using the standard curve equation $y=0.0123 x+0.1476 R^{2}=0.8835$. All the sample were analyzed in triplicate.

\section{Total flavonoid content}

The total flavonoid content of extracted Eucalyptus globulus essential oil was measured by the aluminum chloride colorimetric method (14). In brief, $10 \mu \mathrm{L}$ of oil was made up to $1 \mathrm{~mL}$ of methanol and then mixed with 4 $\mathrm{mL}$ of double distillated water. Then $0.3 \mathrm{~mL}$ of $5 \% \mathrm{NaNO}_{2}$ was added and incubated for $5 \mathrm{~min}$. After incubation 0.3 $\mathrm{mL}$ of $10 \% \mathrm{AlCl}_{3}$ was added and mixture was allowed to stand for 6 minutes. After that $2 \mathrm{~mL}$ of $1 \mathrm{~mol} / \mathrm{L} \mathrm{NaOH}$ 
solution was added and then the final volume of reaction mixture was brought to $10 \mathrm{~mL}$ with double distilled water and incubated for 15 minutes in the dark. After incubation absorbance was measured at $510 \mathrm{~nm}$. Rutin (50$500 \mu \mathrm{g} / \mathrm{mL}$ ) was used in the calibration curve. The result of oil were expressed as mg of rutin equivalent per $10 \mathrm{~kg}$ fresh weight using the standard curve equation $y=0.0005 \mathrm{x} \mathrm{R}^{2}=$ 0.7683 . All the samples were analyzed in triplicate.

\section{Anti-Inflammatory activity (protein denaturation) of the Eucalyptus globulus essential oil}

Protein denaturation essay was done according to the protocol described by Kumar et al., (11) with some modification. The reaction mixture consisted of $0.4 \mathrm{~mL}$ of $1 \%$ BSA, $4.78 \mathrm{~mL}$ of phosphate buffered saline (PBS, $\mathrm{pH}$ 6.4) and different amount of Eucalyptus globulus essential oil. The reaction mixture was incubated in water bath at $37^{\circ} \mathrm{C}$ for 15 minutes. After that reaction mixture was heated at $70^{\circ} \mathrm{C}$ for $5 \mathrm{~min}$. The reaction mixture was immediately cool down. After cooling, the turbidity was measured at 600 nm using UV / VIS spectrophotometer. Phosphate buffer solution was taken as control. Aspirin was taken as standard. The $\%$ inhibition of protein denaturation $=100 \times$ ( 1 - A2 / A1), Where A1 is the absorbance of the control sample and A2 is the absorbance of the test sample.

In addition, protein denaturant assay was also studied using fluorescent assay. The reaction mixture contained $0.4 \mathrm{ml}$ of $1 \%$ BSA, $4.78 \mathrm{~mL}$ of phosphate buffered saline (PBS, $\mathrm{pH}$ 6.4) and $100 \mu \mathrm{l}$ of Eucalyptus globulus essential oil. The reaction mixture was incubated in water bath at $37^{\circ} \mathrm{C}$ for 15 min. After that reaction mixture was heated at $70^{\circ} \mathrm{C}$ for 5 min. After cooling, $1 \mathrm{~mL}$ of mixture was subjected to fluorescent spectroscopy analysis on Perkin Elmer Spectrophotometer (FL6500). The excitation wavelength was $280 \mathrm{~nm}$ and fluorescence emission spectrum was recorded over wavelength range from 300-400 nm. All experiments were done at room temperature $\left(\sim 30^{\circ} \mathrm{C}\right)$.

\section{In vitro Antibacterial activities}

In vitro antibacterial activity of the Eucalyptus globules essential oil was carried out by agar disc diffusion method against 6 test organisms, gram-negative (Acetobacter aceti, Pseudomonas aeruginosa MTCC 427, Escherichia coli MTCC 40), and Gram-positive (Bacillus subtilis MTCC 121, Staphylococcus aureus MTCC 3160) and Saccharomyces cerevisiae strains. Pathogens were purchased from Institute of Microbial Technology, Chandigarh. Sterile paper discs $(6 \mathrm{~mm}$ in diameter $)$ impregnated with $100 \mu \mathrm{l}$ of Eucalyptus globules essential oil. Inoculums of all strains were prepared from 12-h cultures, and OD of suspensions was adjusted to 0.5 at $570 \mathrm{~nm}$ using spectrophotometer. A swab of bacteria suspension was spread on to the petri plates having Luria Broth and allowed to dry for $30 \mathrm{~min}$. The discs with essential oil were then applied and plates were left for 20 min at room temperature to allow to diffusion of oil followed by incubation at $37^{\circ} \mathrm{C}$ for 24 hours. After incubation, the EO diffuses into the luria agar plates and prevent germination and growth of the test microorganism and antibacterial activity was observed as the zone of inhibition around the discs. The experiment was repeated three times.

\section{Chemical fingerprinting}

FPLC fingerprint analysis of essential oil supernatants was carried out using AKTA prime PLUS system (GE healthcare, Sweden), equipped with gradient pump, auto sampler, and Prime view 5.0 software for data acquisition and processing. The analysis was carried out using HiTrap ${ }^{\mathrm{TM}}$ column $(5 \times 5 \mathrm{ml})$ with flow rate $1.0 \mathrm{mLmin}^{-1}$, operating pressure, $1 \mathrm{MPa}(145 \mathrm{psi})$. The fingerprints were registered at wavelength $\lambda=254 \mathrm{~nm}$ and an aliquot of 0.5 $\mathrm{ml}$ was injected for acquiring chromatograms. A preequilibration period of 10 min with $20 \%$ methanol was used between individual runs.

\section{Identification and Quantization}

The four chemical standards - Rutin (in methanol), Tannic acid (in ethanol), Vanillic acid (in methanol), Ascorbic acid (in water) were prepared in appropriate solvents $(25 \mathrm{mg}$ per $\mathrm{ml}$ ) and filtered by $0.2 \mu \mathrm{m}$ filters. Relative peak area (RPA) and Relative retention time (RRT) with respect to related to reference peak were also calculated. The calibration curve for each compound was established by plotting the peak area $(y)$ versus the concentration $(x)$ of each analyte and were fitted to a linear function of type $y=a x+b$. The limit of detection (LOD) and limit of quantification (LOQ) for each analyte at S/N of 3 and 10, respectively. Quantization was established by preparing calibration curves with pure analytes.

\section{Gas Chromatography analysis}

Gas chromatography (GC-FID) analysis of Eucalyptus oil was performed using a Chemtron 2045 gas chromatograph coupled with flame ionization detector. A $2 \mathrm{~m}$ long stainless steel column filed with $10 \% \mathrm{OV}-17$ on $80-100 \%$ mesh Chromosorb W (HP) was used. Nitrogen gas was used as carrier at flow rate of $30 \mathrm{ml} / \mathrm{min}$. The injector and detector temperatures were $250{ }^{\circ} \mathrm{C}$ and $200{ }^{\circ} \mathrm{C}$, respectively and sample $(0.2 \mu \mathrm{l})$ was injected. Ramping conditions for oven were: initially maintained at $50{ }^{\circ} \mathrm{C}$ ramped to $200{ }^{\circ} \mathrm{C}$ at 2 ${ }^{\circ} \mathrm{C} / \mathrm{min}$. The identification of bioactive constituents was achieved by comparison of their relative retention times with either those of known standards or with published data in the literature and matching their mass GC-FID spectra with those obtained from authentic samples and/or the NIST spectral libraries spectra and literature data.

\section{Statistical analysis}

MS Excel software was used to determine $\mathrm{P}$ values by student $\mathrm{t}$ test. Values of $\mathrm{P}<0.05$ were significant. IC50 
values of oil providing $50 \%$ inhibition was calculated at https://www.aatbio.com/tools/ic50-calculator.

\section{Results and Discussion}

\section{Photochemical analysis}

Aromatic plants contain many secondary metabolites and essential oils are one among them which are known to be biological active are poses potent pharmacological activities (8-10). Since oils are plant origin, hence preferred over synthetic ones because of safety concerns (1). Extraction yield of EO from Eucalyptus leaves was about $0.133 \%$. Results of preliminary studies show the phytochemicals composition of essential oil extracted from Eucalyptus leaves (supplementary Table 1). Our results also indicated that total flavonoids and total phenols were estimated to be $392.5 \mathrm{mg} / \mathrm{g} \mathrm{RE}\left(\mathrm{R}^{2}=0\right.$. 9876, $\mathrm{Y}=0.0502 \mathrm{x}+0.7325$ and $3.375 \mathrm{mg} / \mathrm{g} \mathrm{GAE}\left(\mathrm{R}^{2}=0.9885\right.$, $\mathrm{Y}=0.033 \mathrm{x}-0.0273$ ), respectively. The content of flavonoids was dramatically higher as compared to phenols. Earlier literature review also documented that essential oils from Eucalyptus species are rich in polyphenolics like flavonoids $(5,6,8-10,24)$. The presence of high content of flavonoids indicated the effectiveness of EO as potent source of bioactive compounds from Eucalyptus glubolus (15). As a potent source of bioactive compounds EOs have been shown to reduce the risk of many diseases by scavenging free radical in various biological mechanisms (8-10).

\section{Fingerprint analysis}

Secondary metabolite fingerprint characterization by spectroscopy provides valuable insights about qualitative and quantitative formulation of herbal derivatives and bio active components from plants. UV-VIS, fluorescent and FT-IR spectroscopy methods together or separate can be used in this sense as conventional methods for detecting phytocomponents (16). The qualitative UV Spectroscopy profile of essential oil revealed different sharp peaks from 200-250 nm with absorbance of 2.0-2.5 (Fig.1), indicating the accumulation of secondary metabolites (17). Occurrence of peaks at 200-250 nm reveals the presents of flavonoids, and phenolics in essential oil. On comparison of the spectra of extracted oil with literature value, revealed that the oil has some similar flavonoids, and phenolics compounds as reported in by Paulraj et al., (18). Essential oil from Eucalyptus plant species have been reported to be rich source of flavonoids and related volatile constituents (17).

Table 1. Log IC50 of Eucalyptus globulus essential oil for various antioxidant systems

\begin{tabular}{ccc}
\hline Antioxidant assay & Log IC50 \\
\hline & Oil & $\begin{array}{c}\text { Control (Ascorbic } \\
\text { acid) }\end{array}$ \\
\hline Nitric oxide scavenging activity & 48.26 & 57.19 \\
DPPH radical scavenging activity & 70.12 & 9.62 \\
ABTS radical scavenging activity & 15.45 & 127.16 \\
Hydroxyl radical scavenging & 17.94 & 119.38 \\
activity & 18.37 & 59.33 \\
\hline Iron reducing power & & \\
\hline
\end{tabular}

In addition to UV-VIS, fluorescent spectroscopy is more reliable and sensitive method for detection of biomolecules. The fluorescent emission spectrum of essential oil from Eucalyptus is shown in Fig. 2. They are grouped together on the basis of excitation wavelengths. Notably two peaks, one major in green fluorescent region (GF) region and one minor, in far red fluorescent region (FRF) region (fingerprints) were detected. Based on the spectra it was suggested that at least two different florescent substances possibly presented in the Eucalyptus essential oil. It was reported that candidates for GF emission (lambda near $500 \mathrm{~nm}$ ) are, flavonoids, terpenoids and flavins (19). Another set of bioactive compounds, as evidenced by minor peak, was also detected in red-florescent region (FRF) may be due to accumulation of other fluorescent compounds like anthocyanins, phenolics, alkalioids and aromatic benzenoids. Depending on the excitation wavelength, peaks with different intensities were detected. Notably, as excitation wavelength increased, intensity of major peak also increased. Maximum intensity was observed at $\chi 470$. However, intensity of minor peak decreased dramatically from $\chi 390$ to $\chi 470$. Differences in the intensities in fluorescence may be related to chemical composition of essential oil.

Fourier Transform Infrared Spectrophotometer (FT-IR) is perhaps most powerful, rapid, non destructive method to fingerprint plant extracts or powders and for detecting types of bonds and functional groups present in the extracts (16). The IR spectrum region 3000-600 cm-1, (fingerprint) contains absorption bands that characterize the molecular structures by vibrations of the spectrum like deformation, combining, harmonic bands. By interpreting the IR absorption spectrum, the chemical bonds in a compound can be determined.

Table 2. Antimicrobial analysis of essential oil

\begin{tabular}{cccc}
\hline Strain & Strain type & \multicolumn{2}{c}{$\begin{array}{c}\text { Zone of } \\
\text { inhibition }(\mathbf{c m})\end{array}$} \\
\cline { 3 - 4 } & & $\mathbf{C}$ & $\mathbf{E O}$ \\
\hline Acetobacter aceti & Gram negative & 2.1 & FI \\
Pseudomonas aeruginosa & Gram negative & 1.4 & 4.3 \\
Escherichia coli & Gram negative & 1.8 & 2.2 \\
Bacillus subtilis & Gram positive & 3 & 6 \\
Staphylococcus aureus & Gram positive & - & - \\
Saccharomyces cerevisiae & & 2.9 & FI \\
\hline Here: C= Positive control (Vancomycin antibiotic, 10mg), EO= \\
essential oil, FI: 100\% inhibition, -: nil inhibition, values are \\
expressed as mean \pm SD $(n=3)$.
\end{tabular}


Table 3. Anti-inflammatory (protein denaturation activity/BSA denaturation assay) activity of Eucalyptus oil

\begin{tabular}{cc} 
Test sample & Anti-inflammatory activity (\%) \\
\hline Essential oil $(50 \mathrm{ul})$ & $79 \pm 1.2$ \\
Asprin $(200 \mathrm{ug} / \mathrm{ml})$ & $84 \pm 1.8$
\end{tabular}

FT-IR peak values profile and functional groups are documented in Fig. 3. Essential oil showed the presence of bio-active compounds. In FT-IR spectrum gave a broad peak at $2921 \mathrm{~cm}-1$ which indicated the presence of C-H stretching due to alkenes. It showed peaks at about 1457 $\mathrm{cm}-1$ attributed to $\mathrm{C}-\mathrm{H}$ bending due to alkanes. The peak around 1214 and 1079 were due to esters and alcohols. FTIR spectrum confirmed the presence of aromatic compounds, alcohols, phenols, alkanes, alkynes, and amines in Eucalyptus oil (20). All these compounds belong to the secondary plant metabolites as per researcher explanations (18). The presence of above said secondary metabolites could be reason for its various medicinal properties of Eucalyptus essential oil.

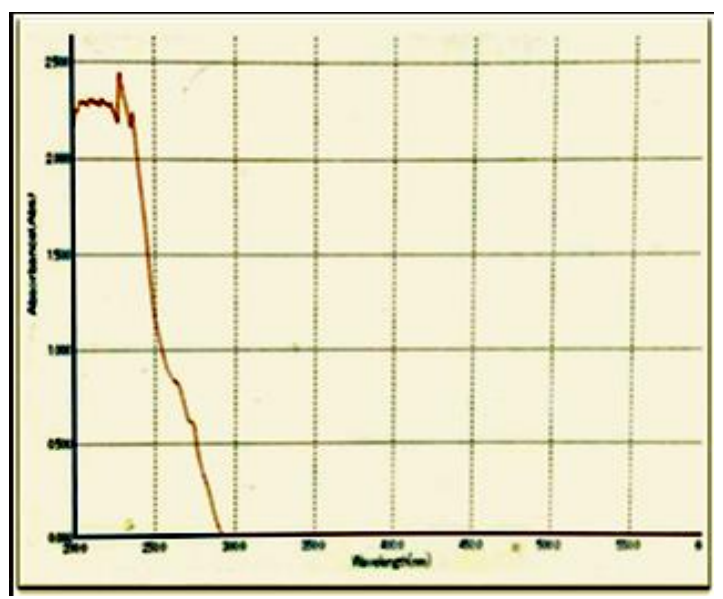

Figure 1. UV Profile of the Eucalyptus globulus essential oil.

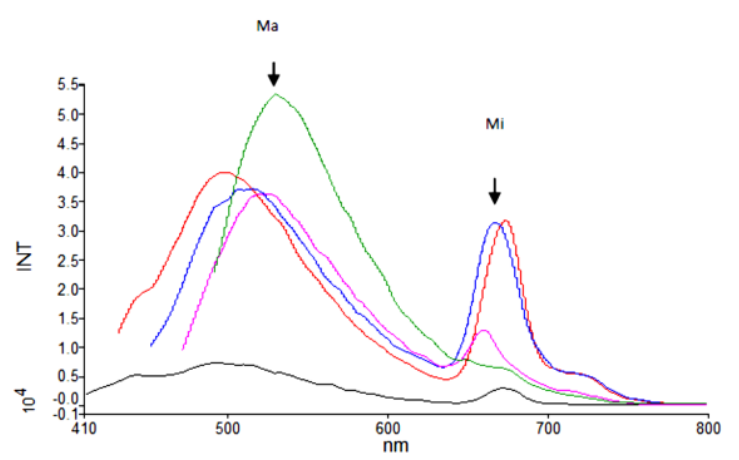

\begin{tabular}{|l|c|c|l|l|}
\hline Xexc & \multicolumn{2}{|c|}{$\begin{array}{c}\text { Peak intensity } \\
\text { (INT) } \times 10^{4}\end{array}$} & \multicolumn{2}{c|}{$\begin{array}{c}\text { Fluorescence } \\
\text { wavelength }\end{array}$} \\
\hline & $\mathrm{Ma}$ & $\mathrm{Mi}$ & $\mathrm{Ma}$ & $\mathrm{Mi}$ \\
\hline $390-$ & 0.5 & 0.3 & 505 & 667 \\
\hline $410-$ & 4.0 & 3.5 & 515 & 673 \\
\hline $430-$ & 3.8 & 3.5 & 524 & 659 \\
\hline 450 & 3.5 & 1.5 & 525 & 670 \\
\hline $470-$ & 5.5 & 1.0 & 508 & 680 \\
\hline
\end{tabular}

Figure 2. Fluorescent analysis of Eucalyptus globulus essential oil.
FT-IR fingerprinting, being a direct and label-free analytical method, can be used as global chemical fingerprints of unknown herbal sample considering the fact that complex mixture are present in herbal products. Furthermore, the identification of bioactive mixture components quantification may be estimated by FT-IR spectra using known calibration standards. FT-IR region can be used to identify the bioactive compound by comparing IR spectra of oil with standard compounds. There were about 12 peaks in the FT-IR fingerprint spectrum (Fig. 3). Peaks 1, 23 and 6 were identified as rutin, tannic acid, vanillic acid and ascorbic acid, respectively by using standards. Rutin, tannic acid vanillic acid and ascorbic acid are polyphenolic compounds widely used in food industry as flavors, preservative and food additive properties. Earlier study has also documented that natural Eucalyptus oil is used in food industries as flavouring agent, in baked goods, confectionery, meat products and beverages (24). Tyagi et al (24), also documented role of Eucalyptus oil as a natural food preservative having antiyeast potential.

\section{Antioxidant Activities}

The antioxidant potential of medicinal plants is the key component generally employed to unravel its therapeutic potential. Earlier studies opined that due to complex nature of antioxidants and phytochemicals, no single assay accurately depicts antioxidant potential, hence two or more methods should be used to evaluate total antioxidant activities (22). Different analysis methods may cover all the possible mechanism of antioxidant potential of bioactive constituents of EO.

In the present study antioxidant activities of essential oil extracted from Eucalyptus glubolus were estimated by various assays like $\mathrm{DPPH}, \mathrm{NO}, \mathrm{OH}^{-}, \mathrm{ABTS}^{+}, \mathrm{O}^{2-}$ radical scavenging assays. Eucalyptus essential oil endowed with powerful antioxidant activities. The IC50 of the essential oil is depicted in table 1 . The performance wise antioxidant potential of Eucalyptus oil was in following order: DPPH (70.12), NO (48.26), $\mathrm{OH}^{-}$(17.94), $\mathrm{ABTS}^{+}$(15.45). The observed reducing power of oil was 18.37. Reducing potential is a significant indicator of compounds which is associated with presence of reductones which break free radical chain by donating hydrogen atom (23). Mostly used therapeutic and pharmacologically drugs used to ameliorate free radicals and oxidative stress related diseases have been reported to have strong reducing power. We therefore opine that the marked antioxidant activities of essential oil may be attributed to the presence of flavonoids and other phenolic compounds as observed in this study. Richness of antioxidant activities of any bioactive compound is the symbol of its potential use as food/drug supplement to control damage of biomolecules by inhibiting free radicals in biological system and consequently rejuvenates the body functions (24). In the past few years, the identification of 
phenolic based derivatives from different plants extracts has become a major area of health- and medical-related research (21).

\section{In vitro antimicrobial activity}

Eucalyptus essential oil was quantitatively assessed for invitro antimicrobial activity using agar disc diffusion method. The essential oil was found to exhibit varying degree of inhibitory activity against all the microbial drug resistant strains. In the present study, essential oil from Eucalyptus showed strong antimicrobial activity with almost all the strains (Table 2).

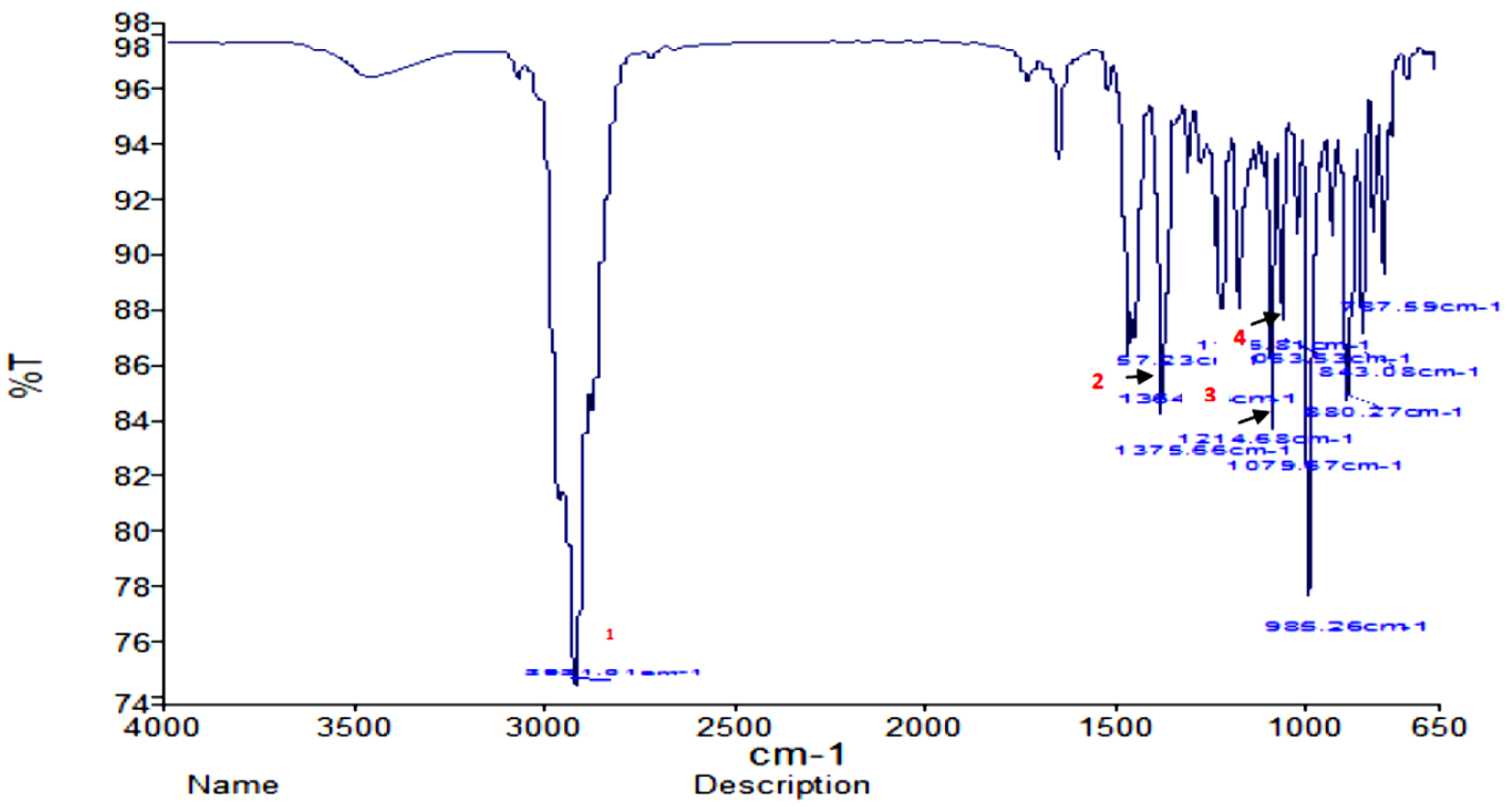

\begin{tabular}{|c|c|c|c|c|c|c|}
\hline Peak Number & $\bar{X}(\mathbf{c m}-\mathbf{l})$ & $\mathbf{Y}(\% \mathbf{T})$ & Vibration mode & Functional grp & intensity & Bioactive molecule \\
\hline 1 & 2921.01 & 74.35 & C-H stretching & alkene & Medium & $\mathrm{RC}^{-}[1,8$ Cineole (Eucalyptol)] \\
\hline 2 & 1457.23 & 87.44 & $\mathrm{C}-\mathrm{H}$ bending & Alkane & High & $\left.[\delta(\mathrm{CH} 3), \delta \text { 9CH2 })^{a}\right)$ \\
\hline 3 & 1375.66 & 84.23 & $\mathrm{~S}=\mathrm{O}$ stretching & Sulphonamide & High & TA [Citronella] \\
\hline 4 & 1364.04 & 85.89 & $\mathrm{~S}=\mathbf{O}$ stretching & Sulphonamide & High & [Menthol] \\
\hline 5 & 1214.68 & 84.59 & C-O stretching & Ester & High & [1,8 Cineole (Eucalyptol)] \\
\hline 6 & 1166.81 & 88.08 & C-O stretching & Aliphatic ether & High & {$[1,8$ Cineole (Eucalyptol)] } \\
\hline 7 & 1079.67 & 83.68 & $\mathrm{C}-\mathrm{O}$ stretching & Primary alcohol & High & VA [1,8 Cineole (Eucalyptol)] \\
\hline 8 & 1053.53 & 87.65 & C-O stretching & Primary alcohol & High & Af $[1,8$ Cineole (Eucalyptol) $]$ \\
\hline 9 & 985.26 & 77.68 & $\mathrm{C}=\mathrm{C}$ bending & Alkene & Medium & [1,8 Cineole (Eucalyptol)] \\
\hline 10 & 880.27 & 85.57 & C-H bending & $1,2,4$ trisubstituted & High & [1,8 Cineole (Eucalvptol)] \\
\hline 11 & 843.08 & 87.19 & $\mathrm{C}=\mathrm{C}$ bending & Alkene & High & [1,8 Cineole (Eucalvptol)] \\
\hline 12 & 787.59 & 89.34 & $\mathrm{C}-\mathrm{H}$ bending & 1,3 disubstituted & High & [Phenvlethyl phenvlacetate] \\
\hline
\end{tabular}

Figure 3. FT-IR analysis of Eucalyptus globulus essential oil.

Data revealed that maximum inhibition (almost full) was noticed for $A$. aceti and $S$. cerevisiae. The essential oil showed strong antimicrobial activity against $P$. aerogenosa and $B$. subtilis. Essential oil showed moderate activity against $E$. coli while inactive against $S$. aureus. The differential action of essential oil and or their constituents may be due to the presence single target or multiple targets for their activity. Consequently, the antimicrobial activities of Eucalyptus oil may be attributed to synergistic effects of polyphenolics. Our findings were in consonance with the earlier studies documenting that oil extracted from eucalyptus leaves posses marked antibacterial activities $(5,8,9)$. Essential oil from Eucalyptus species has been reported to have antibacterial activity due to presence of bioactive molecules like Eucalyptol, citronella (22). Phenolics are reported to be involved in the inhibition of various metabolic and biosynthetic pathways. Silva et al., (8) cited that antimicrobial toxicity of EOs may be attributed to hydrolytic enzyme inhibition (proteases) or inhibited 
interactive partners like: microbial adhesions, cell wall envelop proteins, and non-specific interaction with carbohydrates. Literature revealed that oil induces antimicrobial activities due to the presence of potent bioactive molecules like terpenoids (eugenol and eucalyptol components) flavonoids and other alkaloids (1). These compounds have capability to diffuse across the cell membranes and induce biological reactions and disrupt the proton motive force, electron flow, active transport, and coagulation of the cell contents. Results further revealed that essential oil from Eucalyptus showed dramatic bacteriostatic activity against gram negative bacteria than Gram-positive. It was noteworthy observation as mostly literature suggests that gram negative bacterial are more resistant than gram positive due to complex nature of cell wall (5). Presence of lipopolyscarides and thick peptidoglycan layer, allows gram negative bacteria to be more resistant to most of hydrophobic antibiotics and toxic drugs. Raho and Benali (5) also cited that essential oil from Eucalyptus globules inhibited more growth on gram negative bacteria than gram positive ones.

\section{Anti-protein denaturation studies}

The major cause of tissue inflammation is protein denaturation which is associated with indications like redness, pain, heat, swelling and loss of function at that area of tissues (12). The major reason behind loss of protein functions is the disruption of hydrogen, hydrophobic and disulphide bonds in protein structures. Hence it was deduced that compounds which are able to prevent these changes and inhibit heat induced protein denaturation have potential to be used as therapeutic antiinflammatory drugs. In the present study protein denaturation inhibitory study of essential oil was investigated by fluorescent technique (19). Therefore, in order to study the inhibitory effect of essential oil (EO) from Eucalyptus on protein denaturation process, bovine serum albumin (BSA), a water soluble protein, was chosen. Typical fluorescence spectra for denatured BSA and BSA plus EO are shown in Fig. 4. EO exhibited substantial decrease in inhibition of protein denaturation, as fluorescence intensity decreased substantially after the addition of EO to BSA. The fluorescence intensity using commercial synthetic drugs is also shown in Fig. 4. Further, biochemical protein denaturation assay was also performed to validate the same. As indicated in table 3, EO showed $79 \%$ maximum inhibition. Asprin, a standard anti-inflammatory drug showed $84 \%$ activity. These results clearly indicate the potential of Eucalyptus essential oil as an anti-inflammatory agent. The antidenaturation activity of EO may be ascribed to complex mixtures having multiple compounds which my interact synergistically or the contribution of trace components. The present findings were in corroboration with earlier studies reported on anti-inflammatory potential of eucalyptus oil $(28,29)$.

\section{FPLC fingerprint analysis}

Herbal therapeutic product is a complicated system of mixtures having multiple bioactive constituents. Changes in metabolic profiles of 'botanical drug' can be studied with help of chemical fingerprinting which mainly intended to obtain a particular fingerprint of a specific product.

For such purposes, FPLC fingerprint should be considered to evaluate quality of herbal medicine worldwide (27). This technology provides a comprehensive picture of all active biological and pharmaceutical components in the plant. The results of FPLC fingerprint analysis is shown in Figure 5 and supplementary table 2 . Satisfactory calibration curve with good linearity were obtained with correlation coefficients from 0.93 to 0.99 for all the analytes. The LODs and LOQs for all the analytes are shown in the supplementary table 2, which depicted the sufficient sensitivity of the analytical methods. The FPLC chromatograms showed abundant diversity of chemical constituents which were analyzed by was analyzed by qualitation and quantitation (Figure 5).

Table 4. FPLC analysis of Eucalyptus essential oil

\begin{tabular}{|c|c|c|c|c|c|c|c|c|}
\hline $\begin{array}{c}\text { Peak } \\
\text { no }\end{array}$ & Analyte & RT & Area (\%) & $\begin{array}{c}\text { Area } \\
\text { (mAumin) }\end{array}$ & $\begin{array}{l}\text { Height } \\
(\mathbf{m A u})\end{array}$ & RRT $^{*}$ & $\mathbf{R P A}^{\#}$ & $\begin{array}{c}\text { Content } \\
(\mathrm{mg} / \mathrm{g})\end{array}$ \\
\hline $15^{\$}$ & Tannic acid & 2.87 & 14.0 & 380 & 2424 & 1 & 1 & 30.12 \\
\hline 18 & Ascorbic acid & 4.30 & 4.7 & 128 & 2158 & 1.49 & 0.33 & 10.12 \\
\hline 1 & Rutin & 1.19 & 1.5 & 43 & 1288 & 0.41 & 0.11 & 5.62 \\
\hline 17 & Vannilic acid & 4.25 & 6.7 & 182 & 2106 & 1.48 & 0.47 & 16.23 \\
\hline
\end{tabular}

* The ratio of peak retention time of the target and internal reference substance.

\# The ratio between peak area of target and internal reference standard

\$ The internal reference substance.

The four analytes were identified in essential oil by comparing their retention time with those of standard compounds (Figure 5). There were about 20 characteristic peaks with 6 min, shown in Figure 5. Peaks 1, 15, 17 and 18 were identified as rutin, tannic acid, vannilic acid and ascorbic acid, respectively. The contents of identified compounds are summarized in table 4 . Tannic acid was the major compound identified followed by vannilic acid, ascorbic acid and rutin. The content of analytes varied from 5.62 to $301.2 \mathrm{mg} / \mathrm{g}$. Data showed significant difference in contents of compounds. The other peaks may be attributed to the other unknown bio active compounds. Tannic acid (peak 1) has a considerable high content $14 \%$ of the total evaluated area of peaks, and it 
also had moderate retention time, a stable peak area and good shape. Therefore, it was chosen a reference peak to calculate RRT and RPA. Then RRT and RPA of 4 identified analytes with respect to reference peak were calculated and are shown in table 4.

Table 5. GC-FID identification of bioactive components

\begin{tabular}{cccc}
\hline Peak no & RT $(\mathbf{m i n})$ & Compound & Percentage \\
\hline 1 & 1.08 & citral & 0.34 \\
2 & 12.29 & $\alpha$-pinene & 16.9 \\
3 & 16.59 & $\beta$-pinene & 16.01 \\
4 & 18.99 & $\beta$-myrcene & 7.22 \\
5 & 20.84 & 1,8 cineole & 7.25 \\
6 & 22.81 & 1,8 cineole & 21.69 \\
7 & 26.49 & 4-terpineol & 0.50 \\
8 & 30.58 & $\alpha$-pinene epoxide & 10.73 \\
9 & 33.99 & Cis-limonene oxide & 1.22 \\
10 & 36.58 & Linalool & 1.67 \\
11 & 38.69 & eugenol & 3.78 \\
12 & 76.49 & - & 3.75 \\
13 & 79.33 & - & 7.92 \\
\hline
\end{tabular}
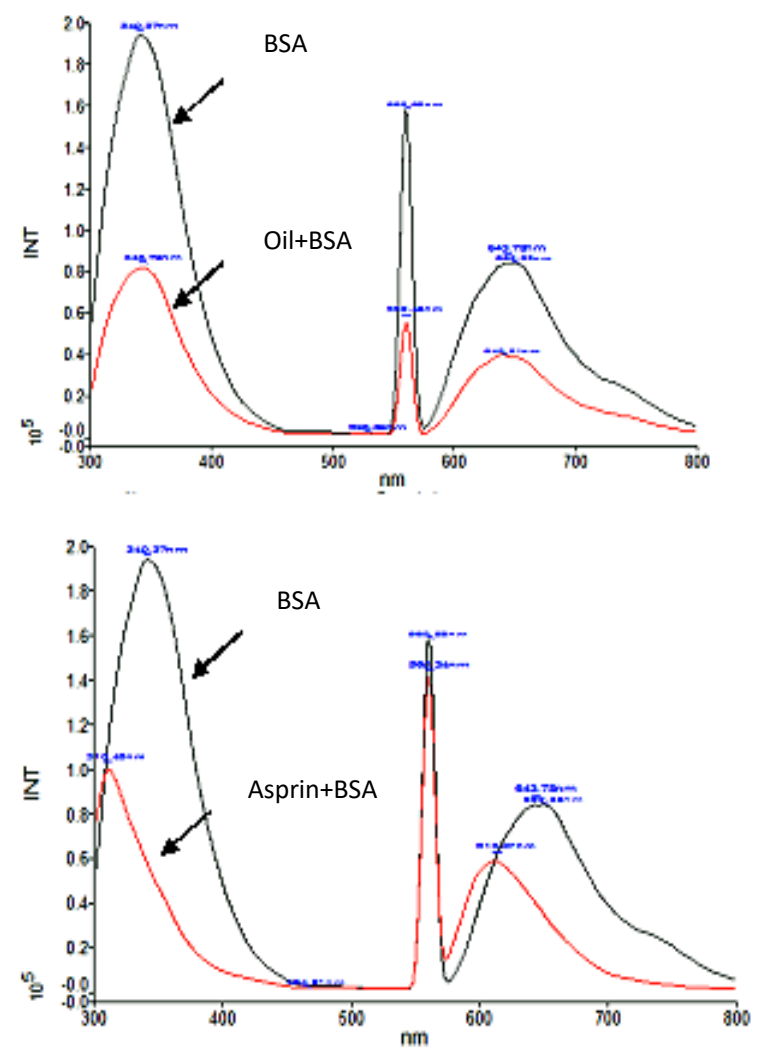

Figure 4. Anti-inflammatory (protein denaturation activity/BSA denaturation assay) activity of Eucalyptus oil using fluorescent technique

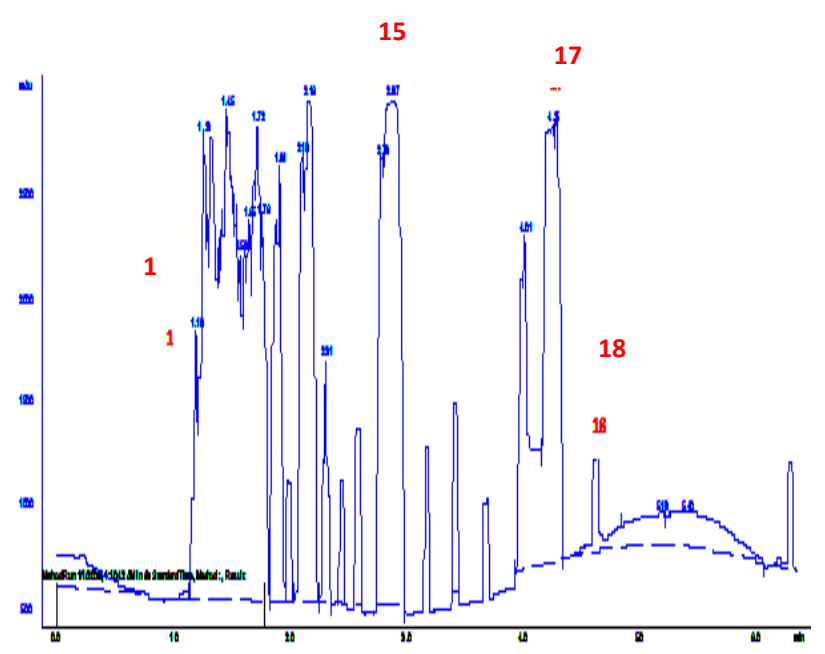

Figure 5. Representative FPLC chromatogram of eucalyptus essential oil. Peaks: $15=$ tannin acid; $18=$ ascorbic acid; $1=$ rutin; $17=$ vannilic acid

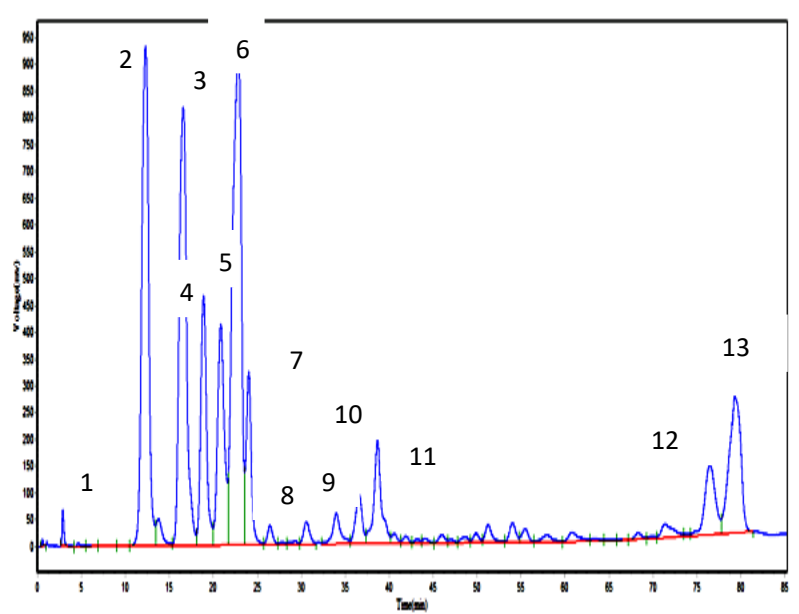

Figure 6. GC-FID chromatogram of Eucalyptus oil

\section{GC-FID analysis}

The bioactive constituents identified by GC-FID analyses were enumerated along with their retention time and concentration (Fig. 6, Table 5). GC-FID analysis of Eucalyptus oil revealed the presence of 42 compounds for the total of $100 \%$. All identified 11 compounds were: citral, $\alpha$-pinene, $\beta$ - pinene, $\beta$-myrcene, 1,8 cineole, 1,8 cineole, 4-terpineol, $\alpha$-pinene epoxide, Cis-limonene oxide, Linalool, and eugenol. GC-FID chromatogram contained three major peaks along with many small peaks indicating the presence of major compounds. The major constituents were 1,8 cineole $(29 \%), \alpha$-pinene $(16.9 \%)$, and $\beta$ - pinene $(16 \%)$, The small peaks may be attributed to the bioactive components present in small quantities or disintegrated major compounds. As reported in literature, eucalyptus essential oil was predominant in 1,8 cineole $(5,6,9,10,24)$. Due to these bio-active components, in the past few years, use of Eucalyptus oil has become a major area of health- and medical-related research. Earlier research also documented that the cineole-based 
Eucalyptus oil is used as major component in pharmaceutical preparations as anti-diabetic, antioxidative, antiviral, antibacterial, antifungal, antitumor, antihistaminic, anticancer cytochrome p450 inhibitor and hepatoprotective effects and also to reduce the symptoms of influenza and colds, in products like cough sweets, lozenges, ointments, toothpastes and inhalants $(5,26)$. Nevertheless recent in-silico studies also documented the role of eucalyptus oil to combat COVID-19 infections (30-32).

\section{Conclusions}

From the above study it was safely concluded that essential oil from underutilized plant Eucalyptus glubolus leaves has appreciable content of polyphenolics along with antioxidant activities, in-vitro antibacterial activity and anti-inflammatory activities. This research clearly raises the possibility that essential oil from this plant having potential health benefits to combat diseases where free radicals have been established as culprits. Therefore this research can be guidelines for researchers in the field of phamagonosy to make more therapeutic drugs from other point of view.

\section{Acknowledgments}

ADS want to thank DST Govt. of India for sanctioning grant for this project under SC/ST Hub.

\section{Conflict of interest}

None to declare.

\section{Supplementary sections}

\section{Preliminary colorimetric analyses test (Qualitative analysis of phytochemicals)}

Eucalyptus globulus essential oil was dissolved in methanol $(0.3 \mathrm{ml} \mathrm{oil} / 2 \mathrm{ml}$ of methanol) analyzed for the presence ofvarious phytochemicals following Kumar et al, (11).

\section{Tests for terpenoids}

Mixture (Eucalyptus globulus essential oil and methanol) was mixed with the chloroform and some drops of concentrated $\mathrm{H}_{2} \mathrm{SO}_{4}$ were added, shaken well, and allowed to stand for some time. Red color appeared at the lower layer indicated the presence of the steroids and formation of yellow color layer indicate the presence of the terpenoids. Methanol was taken as negative control.

\section{Tests for the proteins}

Mixture (Eucalyptus globulus essential oil with methanol) was treated with one drop of $2 \%$ copper sulphate solution. After this $1 \mathrm{~mL}$ of $90 \%$ ethanol was added, followed by the excess of potassium hydroxide pellets. Pink color in ethanol layer indicated the presence of protein. Methanol was taken as negative control.

Tests for amino acid

Two drops of $5 \%$ ninhydrine were added to $1 \mathrm{~mL}$ of mixture of Eucalyptus globulus essential oil and methanol. Amino acid were indicated by purple color. Methanol was taken as negative control.

Tests for phenols

$2 \mathrm{~mL}$ of $2 \%$ ferric chloride was mixed with $1 \mathrm{~mL}$ of mixture of Eucalyptus globulus essential oil and methanol. The presence of blue-green and black coloration indicated the presence of phenols. Methanol was taken as negative control.

\section{Tests for saponins}

$1 \mathrm{~mL}$ of mixture of Eucalyptus globulus essential oil and methanol was mixed well in the water and shaken, the presence of foam indicated the preliminary evidence for the presence of saponins. Methanol alone was taken as the negative control.

\section{Test for carbohydrates}

Benedict's reagent was mixed with the $1 \mathrm{~mL}$ mixture of Eucalyptus globulus essential oil and methanol and slightly boiled, and appearance of reddish-brown precipitate indicated the presence of the carbohydrates. Methanol alone was taken as the negative control.

\section{Test for glycosides}

$0.5 \mathrm{~mL}$ mixture of Eucalyptus globulus essential oil with methanol was taken in a test tube, $0.2 \mathrm{~mL}$ of $10 \%$ ferric chloride solution, and $50 \%$ glacial acetic acid added. 20 ul of sulfuric acid were added and blue color was noticed. Methanol alone was taken as negative control.

\section{Test for flavonoids}

$1 \mathrm{~mL}$ mixture of Eucalyptus globulus essential oil and methanol was taken in a test tube and mixed with the few drops of concentrated HCL and $\mathrm{Mg}$ pallets. The appearance of pink scarlet color is indicated the presence of flavonoids.

\section{References}

1.Chiang LC, Ng LT, Chiang W, Chang MY, Lin CC. Immunomodulatory activities of flavonoids, monoterpenoids, triterpenoids, iridoid glycosides and phenolic compounds of Plantago species. Planta Med. 2003; 69: 600-604.

2. Newman DJ, Cragg GM. Natural products as sources of new drugs from 1981 to 2014. J Nat Prod. 2016; 79: 629-661.

3. Tlili N, Khaldi A, Triki S, Munné-Bosch S. Phenolic compounds and vitamin antioxidants of caper 
(Capparis spinosa). Plant Foods Hum. Nutr. 2010; 65: 260-265.

4.Gao QH, Wu CS, Yu JG, Wang M, Ma YJ, Li CL. Textural characteristic, antioxidant activity, sugar, organic acid, and phenolic profiles of 10 promising jujube (Ziziphus jujuba Mill.) selections. J. Food Sci., 2012; 77:1218-1225.

5. Raho GB, Benali M. Antibacterial activity of the essential oils from the leaves of Eucalyptus globulus against Escherichia coli and Staphylococcus aureus. Asian Pac J Trop Biomed. 2012; 2:739-42.

6. Batish DR, Singh HP, Kohli RK, Kaur S. Eucalyptus essential oil as a natural pesticide. For. Ecol. Manage., 2008; 256: 2166-2174.

7. Michalak A. Phenolic Compounds and Their Antioxidant Activity in Plants Growing under Heavy Metal Stress. Polish J of Environ Stud. 2006; 15: 523530 .

8. Silva J, Abebe W, Sousa SM, Duarte VG, Machado MIL, Matos FJA. Analgesic and anti-inflammatory effects of essential oils of Eucalyptus. J Ethnopharmacol. 2003; 89:277-83.

9. Su YC, Ho CL, Wang EI, Chang ST. Antifungal activities and chemical compositions of essential oils from leaves of four Eucalyptus. Taiwan J For Sci. 2006; 21:49-61.

10. Siramon P, Ohtani Y. Antioxidative and antiradical activities of Eucalyptus camaldulensis leaf oils from Thailand. J Wood Sci. 2007; 53:498-504.

11. Kumar V, Singh S, et al. Determination of phytochemical, antioxidant, antimicrobial, and protein binding qualities of hydroethanolic extract of Celastrus paniculatus. Journal of Applied Biology \& Biotechnology. 2018; 6 : 11-17.

12. Obafemi TO, Akinmoladun AC, Olaleye MT, et al. High Performance Liquid Chromatography (HPLC) Fingerprinting, Mineral Composition and In Vitro Antioxidant Activity of Methanol Leaf Extract of Synsepalum dulcificum (Sapotaceae). J Applied Pharma Science 2017; 7 : 110-118.

13. Khan RA, Khan MR, Sahreen S, Ahmed M. Assessment of flavonoid contents and in vitro antioxidant activity of Launaea procumbens. Chemistry Central Journal, 2012; 6:43.

14. Baba SA, Malik SA. Determination of total phenolic and flavonoid content, antimicrobial and antioxidant activity of a root extract of Arisaema jacquemontii Blume. J of Taibah University for Science 2015; 9: 449-454.

15. Medini F, Fellah H, Ksouri R, Abdelly C. Total phenolic, flavonoid and tannin contents and antioxidant and antimicrobial activities of organic extracts of shoots of the plant Limonium delicatulum. J of Taibah University for Science, 2014, 8: 216-224.

16. Chen JB, Sun SQ, Tang XD, Zhang JZ, Zhou Q. Direct and simultaneous detection of organic and inorganic ingredients in herbal powder preparations by Fourier transform infrared microspectroscopic imaging. Spectrochim. Acta A. 2016; 165:176-182.
17. Parekh J, Chanda V. In vitro Antimicrobial activity and Phytochemical analysis of some Indian medicinal plants. Turk J of Biol. 2007; 31:53-58.

18. Paulraj K, Irudayaraj V, Johnson M, Patric D. Phytochemical and anti-bacterial activity of epidermal glands extract of Christella parasitica (L.) H. Lev. Asian Pac. J. Trop Biomed. 2011;1:8-11.

19. Mylle E, Codreanu MC, Boruc J, Russinova E. Emission spectra profiling of fluorescent proteins in living plant cells. Plant Methods. 2013; 9:1-8.

20. Liu H-X, Sun S-Q, LvG-H, Chan KKC. Study on Angelica and it's a different extracts by Fourier Transform Infrared Spectroscopy and Two dimensional correlation. IR Spectroscopy. Spectrochimica acta. Part A, Mol Biomol Spectroscopy. 2006; 64(2): 321-e6.

21. Baranska M, Schulz H, Reitzenstein S, Uhlemann U, Strehle MA, Krüger $\mathrm{H}$, et al. Vibrational spectroscopic studies to acquire a quality control method of Eucalyptus essential oils. Biopolymers. 2005; 78: 237-248.

22. Swamy MK, Akhtar MS, Sinniah UR. Antimicrobial Properties of Plant Essential Oils against Human Pathogens and Their Mode of Action: An Updated Review", Evidence-Based Complementary and Alternative Medicine, 2016; Article ID 3012462, 21 pages.Chiang LC, Ng LT, Chiang W, Chang MY, Lin C. Immunomodulatory activities of flavonoids, monoterpenoids, triterpenoids, iridoid glycosides and phenolic compounds of Plantago species. Planta Med. 2003; 69: 600-604.

23. Harborne JB, Baxter H, Chemical Dictionary of Economic Plants (University of Reading, UK). John Wiley \& Sons, New York, NY. 2001. ISBN 047149226-4.

24. Tyagi K, Bukvicki A, Gottardi D, Tabanelli D, Montanari G, Malik C, et al. Eucalyptus Essential Oil as a Natural Food Preservative: In Vivo and In Vitro Antiyeast Potential. BioMed Research International. 2014; 10.1155/2014/969143.

25. Kushwaha, N, Chandra S, \& Singh C, Pharmacy K, Puramufit K, \& Kesharwani PU, et al. A review on therapeutics application of Eucalyptus oil. Int $\mathrm{J}$ of Herbal Med. 2018; 6:110-115.

26. Madadlou A, Sullivan SO, Sheehan D, Fast protein liquid chromatography. Methods Mol Biol, 2011; 681: 439-47.

27. Silva J, Abebeb W, Sousa SM, Duarte VG, Machado MIL, Matos, FJA. Analgesic and anti-inflammatory effects of essential oils of Eucalyptus. Journal of Ethnopharmacol. 2003; 89:277-283.

28. Taur DJ, Kulkarni VB, Patil RY. Chromatographic evaluation and anthelmintic activity of Eucalyptus globules oil. Pharmacognosy Res. 2010; 2:125-127.

29. Sharma AD, Kaur I. Molecular docking and pharmacokinetic screening of eucalyptol (1,8 cineole) from eucalyptus essential oil against SARS-CoV-2. 2020; Notulae Scientia Biol. 12:536-545 
30. Sharma AD, Kaur I. Eucalyptol (1,8 cineole) from eucalyptus essential oil a potential inhibitor of COVID 19 corona virus infection by molecular docking studies. 2020; Preprints at:https://doi.org/10.20944/preprints202003.0455.v1.

31. Sharma AD, Kaur I. Molecular docking studies on jensenone from eucalyptus essential oil as a potential inhibitor of COVID 19 corona virus infection. Res Rev Biotechnol Biosci 2020; 1:59-66. 


\section{Suplementary Material}

Supplementary Table 1. Phytochemical analysis of Eucalyptus globulus essential oil

\begin{tabular}{cc}
\hline Phytochemicals & Results \\
\hline Saponins & Positive \\
Flavonoids & Positive \\
Terpenoids & Positive \\
Carbohydrates & Negative \\
Amino acids & Negative \\
Protein & Negative \\
Phenol & Negative \\
Glycosides & Negative \\
\hline Total flavonoids and phenolic content & \\
\hline Total flavonoids & $392.5 \mathrm{mg} / \mathrm{gRE}$ \\
Total phenols & $3.375 \mathrm{mg} / \mathrm{gGAE}$ \\
\hline
\end{tabular}

Supplementary Table 2. Linearity, LODs and LOQs for different analytes

\begin{tabular}{ccccccc}
\hline SNO. & \multirow{2}{*}{ ANALYTE } & $\begin{array}{c}\text { REGRESSION } \\
\text { EQUATION }\end{array}$ & $\mathbf{R}^{\mathbf{2}}$ & $\begin{array}{c}\text { LINEAR } \\
\mathbf{R A N G E}(\boldsymbol{\mu g} / \mathbf{m l})\end{array}$ & $\mathbf{L O D}^{\mathbf{b}}(\boldsymbol{\mu g} / \mathbf{m l})$ & $\mathbf{L O Q}^{\mathbf{b}}(\boldsymbol{\mu g} / \mathbf{m l})$ \\
\hline 4 & Tannic acid & $\mathrm{y}=2.77 \mathrm{x}+0.12$ & 0.981 & $5-20$ & 0.57 & 1.75 \\
7 & Vanillic acid & $\mathrm{y}=36 \mathrm{x}+7.333$ & 0.938 & $5-20$ & 8.8 & 26.8 \\
8 & Rutin & $\mathrm{y}=0.895 \mathrm{x}-0.286$ & 0.962 & $5-25$ & 0.24 & 0.75 \\
9 & Ascorbic acid & $\mathrm{y}=0.035 \mathrm{x}-0.006$ & 0.993 & $5-20$ & 0.21 & 0.65 \\
\hline
\end{tabular}

${ }^{\mathrm{a}} \mathrm{y}$ and $\mathrm{x}$ respectively, the peak areas and concentrations of the analytes.

${ }^{b}$ LOD limit of detection ( $\left.\mathrm{S} / \mathrm{N}=3\right)$, LOQ limit of quantification $(\mathrm{S} / \mathrm{N}=10)$.
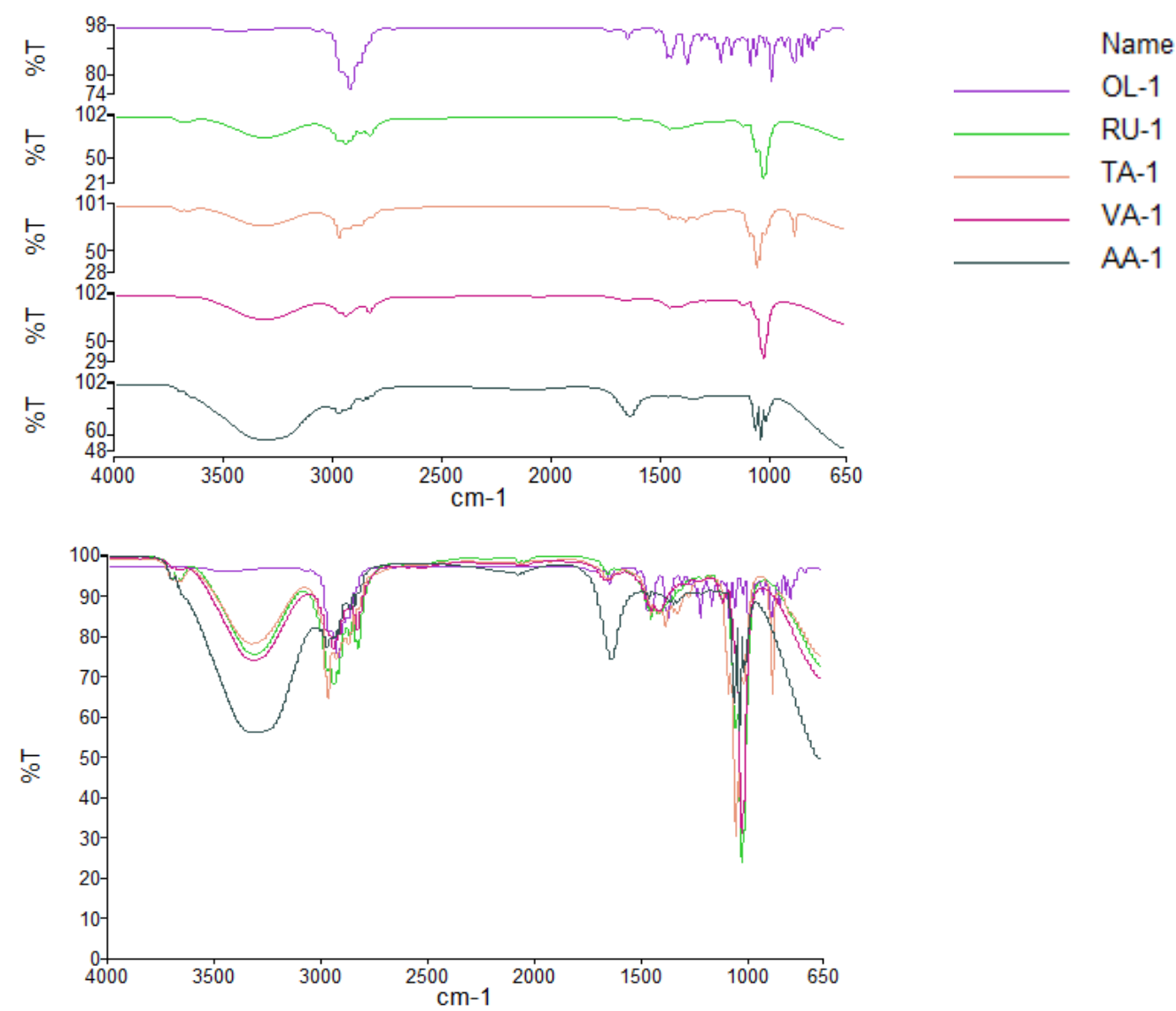

Supplementary Figure 1. FT-IR spectra of essential oil and standards. OL1: oil, RU1: rutin, TA1: tannic acid, VA1:vanillic acid, AA1; ascorbic acid 